\title{
The Neurospora crassa CYT-18 protein C-terminal RNA-binding domain helps stabilize interdomain tertiary interactions in group I introns
}

\author{
XIN CHEN, ${ }^{1,2}$ GEORG MOHR, ${ }^{1}$ and ALAN M. LAMBOWITZ ${ }^{1}$ \\ ${ }^{1}$ Institute for Cellular and Molecular Biology, Department of Chemistry and Biochemistry, and Section of Molecular \\ Genetics and Microbiology, School of Biological Sciences, University of Texas at Austin, Austin, Texas 78712, USA
}

\begin{abstract}
The Neurospora crassa mitochondrial tyrosyl-tRNA synthetase (CYT-18 protein) promotes the splicing of group I introns by stabilizing the catalytically active RNA structure. To accomplish this, CYT-18 recognizes conserved structural features of group I intron RNAs using regions of the N-terminal nucleotide-binding fold, intermediate $\alpha$-helical, and C-terminal RNA-binding domains that also function in binding tRNA ${ }^{\mathrm{Tyr}}$. Curiously, whereas the splicing of the $N$. crassa mitochondrial large subunit rRNA intron is completely dependent on CYT-18's C-terminal RNA-binding domain, all other group I introns tested thus far are spliced efficiently by a truncated protein lacking this domain. To investigate the function of the C-terminal domain, we used an Escherichia coli genetic assay to isolate mutants of the Saccharomyces cerevisiae mitochondrial large subunit rRNA and phage T4 $t d$ introns that can be spliced in vivo by the wild-type CYT-18 protein, but not by the C-terminally truncated protein. Mutations that result in dependence on CYT-18's C-terminal domain include those disrupting two long-range GNRA tetraloop/ receptor interactions: L2-P8, which helps position the P1 helix containing the 5'-splice site, and L9-P5, which helps establish the correct relative orientation of the P4-P6 and P3-P9 domains of the group I intron catalytic core. Our results indicate that different structural mutations in group I intron RNAs can result in dependence on different regions of CYT-18 for RNA splicing.
\end{abstract}

Keywords: aminoacyl-tRNA synthetase; GNRA tetraloop; ribozyme; RNA structure

\section{INTRODUCTION}

The Neurospora crassa mitochondrial (mt) tyrosyl-tRNA synthetase (TyrRS), the CYT-18 protein, functions in splicing group I introns by stabilizing the catalytically active RNA structure (Akins and Lambowitz 1987; Guo and Lambowitz 1992; Mohr et al. 1992; Caprara et al. 1996a,b; Myers et al. 2002). The group I intron catalytic core consists of two extended helical domains, one formed by the coaxial stacking of secondary structure elements P5, P4, and P6 (P4-P6 domain) and the other consisting of $\mathrm{P} 8, \mathrm{P} 3, \mathrm{P} 7$, and $\mathrm{P} 9$ (P3-P9 domain; Michel and Westhof 1990; Cech 1993; Golden et al. 1998). The juxtaposition of the two domains

Reprint requests to: Alan M. Lambowitz, Institute for Cellular and Molecular Biology, University of Texas at Austin, 1 University Station, A4800, Austin, Texas 78712, USA; e-mail: lambowitz@mail.utexas.edu; fax: (512) 232-3420.

Present address: ${ }^{2}$ Department of Pediatrics, Box 0978, University of California, San Francisco, San Francisco, CA 94143-0978, USA.

Article and publication are at http://www.rnajournal.org/cgi/doi/ 10.1261/rna.5212604. creates a cleft that binds the $5^{\prime}$ and $3^{\prime}$ splice sites and guanosine cofactor and positions them relative to three catalytically essential $\mathrm{Mg}^{2+}$ ions to promote splicing (Shan et al. 2001). CYT-18 interacts with the group I intron catalytic core on the side opposite the active-site cleft (Caprara et al. 1996b). Biochemical and genetic studies have led to a model in which CYT-18 binds first to the P4-P6 domain to promote its assembly and then makes additional contacts with the P3-P9 domain to stabilize the two major RNA helical domains in the correct relative orientation to form the intron's active site (Caprara et al. 1996a,b; Webb et al. 2001; Myers et al. 2002).

CYT-18 appears to have adapted to function in splicing by recognizing conserved tRNA-like structural features of group I intron RNAs (Caprara et al. 1996a; Myers et al. 2002). CYT-18 and other mt TyrRSs are class I aminoacyltRNA synthetases homologous to well-studied bacterial TyrRSs (Fig. 1). These proteins function as homodimers and consist of an N-terminal nucleotide-binding fold domain, which binds the acceptor stem of the tRNA, followed by intermediate $\alpha$-helical and C-terminal tRNA-binding 
domains, which bind the anticodon stem-loop and variable arm (Fig. 1; Brick et al. 1989; Yaremchuk et al. 2002). The C-terminal domain, which contains a region structurally homologous to ribosomal protein S-4, is linked to the remainder of the protein via a flexible hinge (Guez et al. 2000; Yaremchuk et al. 2002). Analysis of site-directed mutations showed that regions of CYT-18 required for splicing are distributed throughout the protein and overlap those required for binding tRNA ${ }^{\text {Tyr }}$ (Kittle Jr. et al. 1991). Further, directed hydroxyl-radical cleavage assays using $\mathrm{Fe}(\mathrm{II})$-EPD incorporated at sites of single cysteine substitutions showed that different regions of CYT-18 interact with structurally similar regions in group I introns and tRNAs (Myers et al. 2002). Thus, CYT-18's intermediate $\alpha$-helical and C-terminal domains interact primarily with the P4-P6 stacked helices, the cognate of the D-anticodon arm stacked helices of the tRNA, and possibly with P2 and P8, whereas the nucleotide-binding fold interacts around the junction of P5 and $\mathrm{P} 9$, a region that overlaps the tRNA's acceptor stem in three-dimensional alignments (Fig. 1).

Although all bacterial and mt TyrRSs share the same basic structure, only the N. crassa mt TyrRS and that of the closely related fungus Podospora anserina have been found to function in group I intron splicing, whereas the Escherichia coli TyrRS and Saccharomyces cerevisiae $\mathrm{mt}$ TyrRS do not function in splicing (Akins and Lambowitz 1987; Kämper et al. 1992; G. Mohr and A.M. Lambowitz, unpubl.). The implication is that the N. crassa and $P$. anserina proteins have adaptations of the basic TyrRS structure that confer splicing activity. These adaptations include an $\alpha$-helical N-terminal extension (denoted $\mathrm{H} 0$ ) and a small insertion in the nucleotide-binding fold region (insertion II), which are not present in TyrRSs that do not function in splicing (Fig. 1; Cherniack et al. 1990; Mohr et al. 2001; P. Paukstelis, R. Coon, L. Madabusi, J. Nowakowski, A. Monzingo, R. Robertus, and A. Lambowitz, in prep.) In addition,

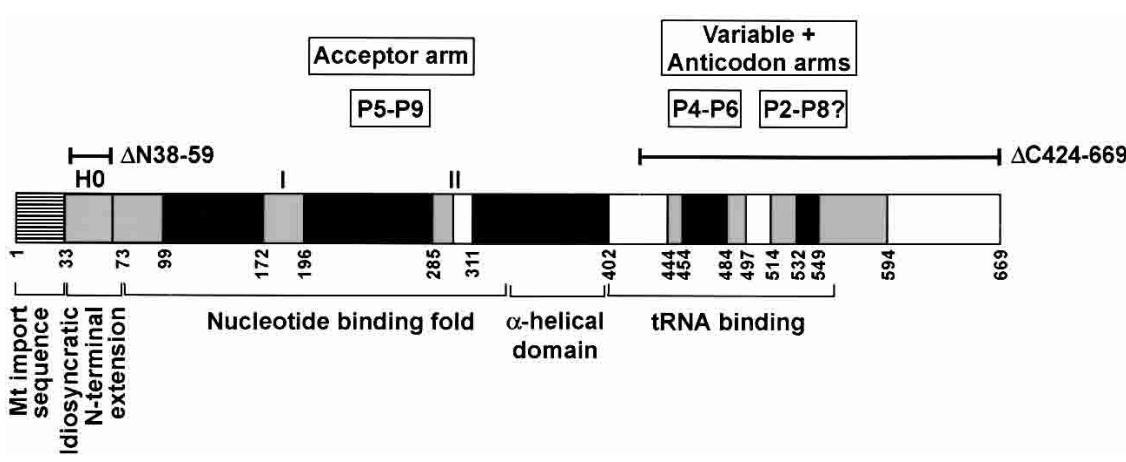

FIGURE 1. Map of the CYT-18 protein. Protein domains are indicated below, and interacting regions of tRNA ${ }^{\text {Tyr }}$ and group I intron RNAs are shown above (Myers et al. 2002). Black boxes indicate regions conserved among all bacterial and $\mathrm{mt}$ TyrRSs, and gray boxes indicate regions strongly conserved only between the $N$. crassa and P. anserina mt TyrRSs, which function in group I intron splicing. The latter regions include an idiosyncratic $\mathrm{N}$-terminal extension ( $\mathrm{H} 0)$ and insertions I and II in the nucleotide-binding fold. The boundaries of the N-terminal truncation mutant $\Delta \mathrm{N} 38-59$ and the C-terminal truncation mutant $\Delta \mathrm{C} 424-669$ are indicated above.
CYT-18's C-terminal domain contains multiple insertions and a long extension that make it more than twice the size of those of bacterial TyrRSs. Interestingly, a mutant CYT-18 protein lacking the $\mathrm{H} 0$ extension $(\Delta \mathrm{N} 39-59)$ is unable to bind stably or splice the $N$. crassa ND1 intron, but retains substantial splicing activity with the mt LSU intron (Mohr et al. 2001). Conversely, a truncated mutant protein that lacks the C-terminal RNA-binding domain $(\Delta \mathrm{C} 424-669)$ is unable to bind stably or splice the N. crassa mt LSU intron, but retains substantial splicing activity with the ND1 intron and all other group I introns tested thus far (Mohr et al. 1992, 2001; G. Mohr, G. Wallweber, and A.M. Lambowitz, unpubl.).

Iodine footprinting experiments with the $N$. crassa $\mathrm{mt}$ LSU and ND1 introns suggest that both introns form similar complexes with CYT-18 despite their differing requirements for CYT-18's N- and C-terminal domains (Caprara et al. 1996a,b). In both introns, most of the putative CYT-18 protection sites on the phosphodiester backbone are in the P4-P6 domain extending from L5 to P6a, with additional sites in the P3-P9 domain, particularly in P9/L9 and P8. According to three-dimensional models based on the $\mathrm{Fe}(\mathrm{II})$-EPD directed hydroxyl radical cleavage experiments, most of the protections reflect interactions with CYT-18's nucleotide-binding and intermediate $\alpha$-helical domains, with the C-terminal domain potentially contributing additional interactions with $\mathrm{P} 8$ and $\mathrm{P} 3$ in both introns, and with $\mathrm{P} 2$ and distal regions of $\mathrm{P} 6 \mathrm{a} / \mathrm{b}$ in the $\mathrm{mt} \mathrm{LSU}$ intron (Caprara et al. 1996a; Myers et al. 2002). Further, although the C-terminally truncated protein can still splice the ND1 intron, the $\mathrm{k}_{\text {off }}$ for the complex is increased about fivefold, suggesting that it still contributes to binding the ND1 intron, even though the interaction is not critical for RNA splicing (Mohr et al. 2001). Together, these findings suggest that although different regions of the protein may make different contributions to the binding affinity for different introns, all group I introns form similar complexes involving the nucleotide-binding fold, intermediate $\alpha$-helical, and C-terminal domains of CYT-18.

Here, we tested this hypothesis and investigated the function of CYT-18's Cterminal domain by isolating mutants of the $S$. cerevisiae mt large subunit rRNA and phage $\mathrm{T} 4 \mathrm{td}$ introns that can be spliced by the wild-type CYT-18 protein, but not by the C-terminally truncated protein. We find that CYT-18's Cterminal domain is required to suppress a variety of intron structural mutations, including those disrupting two longrange GNRA tetraloop/receptor interactions, L2-P8 and L9-P5. Our results suggest that CYT-18's C-terminal domain is required to compensate for specific structural deficiencies in some group I introns. 


\section{RESULTS}

An $E$. coli genetic screen for $S$. cerevisiae $\mathrm{mt}$ LSU intron mutants, whose splicing requires CYT-18's C-terminal domain

To study the function of CYT-18's C-terminal domain, we focused initially on the $S$. cerevisiae mt LSU intron, which is closely related to the N. crassa mt LSU intron (61\% identity) and thus is expected to form a similar complex with CYT18. The S. cerevisiae $\mathrm{mt}$ LSU intron self-splices in vitro, but structurally defective mutants lose this ability and become dependent on CYT-18 (G. Mohr, G. Wallweber, and A.M. Lambowitz, unpubl.). Further, experiments using an E. coli genetic assay (Fig. 2) showed that the splicing of a $\Delta$ ORFderivative of the S. cerevisiae mt LSU intron is dependent on CYT-18 in vivo, but does not require CYT-18's C-terminal domain. Thus, we reasoned that it might be possible to
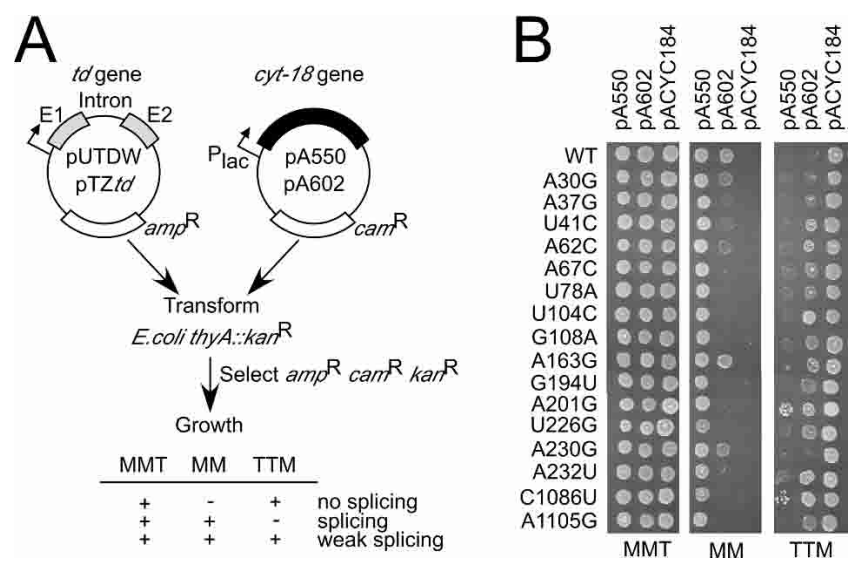

FIGURE 2. E. coli genetic assay of CYT-18-dependent group I intron splicing and growth phenotypes of wild-type and mutant $S$. cerevisiae $m t$ LSU- $\Delta$ ORF introns with different degrees of dependence on CYT18's C-terminal domain. (A) Schematic of the assay. An E. coli thyA disruptant (1904; C600 thyA:: $\left.\mathrm{kan}^{\mathrm{R}}\right)$ was cotransformed with a pUTDW- or pTZtd-based plasmid containing the phage T4 td gene interrupted by the $S$. cerevisiae $\mathrm{mt}$ LSU or phage T4 $t d$ group I introns, respectively, and pA550 or pA602, which express wild-type or Cterminally truncated CYT-18 proteins, respectively. Splicing of the group I intron leads to the production of thymidylate synthetase, which enables cells to grow on minimal medium (MM) in the absence of thymine, but confers sensitivity to trimethoprim, as seen by an inability to grow on minimal medium containing thymine plus trimethoprim (TTM; $\mathrm{Td}^{+}$phenotype). By contrast, cells containing splicing-defective introns or CYT-18 proteins are unable to grow on MM and are resistant to trimethoprim on TTM ( $\mathrm{Td}^{-}$phenotype). Different degrees of splicing can be distinguished by growth phenotypes on different media, as described in Materials and Methods. (B) Growth phenotypes for the wild-type and representative mutant $S$. cerevisiae $\mathrm{mt}$ LSU introns. pUTDW plasmids containing the $t d$ gene interrupted by wild-type or mutant $S$. cerevisiae mt LSU- $\Delta$ ORF introns were cotransformed into E. coli strain 1904 with plasmids pA550 or pA602, which express the wild-type or C-terminally truncated CYT-18 proteins, respectively, or with the vector pACYC184. Transformants were selected by plating on LB medium containing thymine plus antibiotics and then replated on minimal medium plus thymine (MMT), MM, and TTM containing the same antibiotics and grown overnight at $37^{\circ} \mathrm{C}$. The mutant introns are listed on the left. isolate mutants of the S. cerevisiae intron with structural defects whose rescue is dependent on CYT-18's C-terminal domain, thereby providing insight into the function of that domain.

For genetic assays, we constructed plasmid pUTDW $\Delta$ ORF, which contains a 328-nt $\Delta \mathrm{ORF}$ derivative of the S. cerevisiae $\mathrm{mt} \mathrm{LSU}$ intron inserted into an intronless phage T4 thymidylate synthetase $(t d)$ reporter gene, enabling us to use a previously described $t d$ plating assay for CYT-18-dependent splicing (Fig. 2A; Mohr et al. 1992). In this assay, a plasmidborne $t d$ gene interrupted by a group I intron is cotransformed into an E. coli thy $A^{-}$disruptant with a second plasmid expressing the CYT-18 protein. Splicing of the intron leads to the production of thymidylate synthetase, enabling cells to grow on minimal medium (MM) and conferring sensitivity to trimethoprim on minimal medium containing thymine (TTM; $\mathrm{Td}^{+}$phenotype). By contrast, cells containing splicing-defective introns or nonfunctional CYT-18 proteins are unable to grow on minimal medium and are resistant to trimethoprim on medium containing thymine ( $\mathrm{Td}^{-}$phenotype). Different degrees of splicing can be distinguished by growth rates on different media, as described below and in Materials and Methods. Further, experiments with the $t d$ intron have shown a good correlation between the splicing phenotype in vivo and the rate of splicing at physiological $\mathrm{Mg}^{2+}$ concentrations in vitro (Mohr et al. 1992; Myers et al. 1996; Chen et al. 2000; Waldsich et al. 2002).

To carry out genetic screens with the S. cerevisiae mt LSU intron, we generated a library of mutant introns in pUTDW $\triangle$ ORF by mutagenic PCR. This library was cotransformed into E. coli thy $A^{-}$strain 1904 with plasmid pA602, which expresses a truncated CYT-18 protein lacking the C-terminal domain (amino acid residues 424-669). Colonies were then selected on minimal medium supplemented with thymine and tested for their Td phenotype by plating on minimal medium (MM), minimal medium plus thymine (MMT), and minimal medium plus thymine plus trimethoprim (TTM). Plasmids containing mutant introns that gave a $\mathrm{Td}^{-}$or weak $\mathrm{Td}^{+}$phenotype with the C-terminally truncated CYT-18 protein were reisolated and cotransformed into the same E. coli strain with plasmid pA550, which expresses the wild-type CYT-18 protein. $\mathrm{Mu}-$ tants that then showed a stronger $\mathrm{Td}^{+}$phenotype $(8-10 \%$ of those screened) were classified as CYT-18 C-terminal domain-dependent mutants. Plating assays for the wild-type $S$. cerevisiae $\mathrm{mt}$ LSU- $\Delta$ ORF intron and representative mutants with different degrees of dependence on CYT-18's C-terminal domain are shown in Figure 2B.

We sequenced 40 mutant introns, of which 25 contained single nucleotide changes. The single mutations are summarized in Table 1, and their locations are shown on secondary and tertiary structure models of the S. cerevisiae $\mathrm{mt}$ LSU intron in Figure 3. In the secondary structure model, nucleotide residues identical to those in the $N$. crassa $\mathrm{mt}$ 
TABLE 1. In vivo splicing phenotypes of randomly selected CYT18 C-terminal domain-dependent mutants of the $S$. cerevisiae $\mathrm{mt}$ LSU intron

\begin{tabular}{|c|c|c|c|c|}
\hline \multirow[b]{2}{*}{ Mutants $^{\mathrm{a}}$} & \multicolumn{3}{|c|}{ Splicing phenotype ${ }^{b}$} & \multirow{2}{*}{$\begin{array}{c}\text { Secondary } \\
\text { structural element }\end{array}$} \\
\hline & - CYT-18 & $+\mathrm{pA} 550^{\mathrm{c}}$ & $+\mathrm{pA} 602^{\mathrm{d}}$ & \\
\hline Wild type & - & +++ & +++ & - \\
\hline A30G & - & +++ & ++ & L2 \\
\hline A37G & - & +++ & + & P2 \\
\hline U41C & - & +++ & + & P2a bp-1 \\
\hline $\mathrm{A} 62 \mathrm{C}$ & - & +++ & + & P2a bp-1 \\
\hline G63A & - & +++ & - & $\mathrm{J} 2 \mathrm{a} / 3$ \\
\hline A65U & - & +++ & - & $\mathrm{J} 2 \mathrm{a} / 3$ \\
\hline A67C & - & +++ & - & $J 2 a / 3$ \\
\hline U78A & - & +++ & - & P4 bp-1 \\
\hline U104C & - & +++ & - & L5 \\
\hline U107G & - & +++ & - & P5 \\
\hline G108A & - & ++ & - & P5 \\
\hline A163G & - & +++ & ++ & P6a \\
\hline A185G & - & +++ & - & p7.1 \\
\hline G194U & - & +++ & - & P11 \\
\hline A201G & - & ++ & - & J7.1/7.1a \\
\hline A222U & - & ++ & - & P3 \\
\hline U226G & - & +++ & - & P8 \\
\hline A230G & - & +++ & ++ & P8 \\
\hline $\mathrm{A} 232 \mathrm{U}$ & - & ++ & - & P8 \\
\hline A233G & - & +++ & - & P8 \\
\hline U1064G & - & +++ & - & P8 \\
\hline U1075A & - & +++ & - & $\mathrm{J} 7 / 8$ \\
\hline C1086U & - & ++ & - & P9 \\
\hline A1105G & - & +++ & - & P9.1 \\
\hline U1111C & - & +++ & - & P9.1 \\
\hline
\end{tabular}

${ }^{a}$ Mutants are named according to the site of mutation and altered nucleotide residue.

${ }^{b}$ Splicing phenotypes are defined as described in Materials and Methods, based on at least two repeats of the $t d$ plating assay for each mutant.

${ }^{\mathrm{C}} \mathrm{pA} 550$ expresses full-length CYT-18 protein.

${ }^{d}$ pA602 expresses C-terminally truncated CYT-18 protein.

LSU intron are shown in italics. The largest number of mutations (14 of 25) were found in or near P2 and P8, two regions that are brought into proximity via the L2-P8 GNRA tetraloop/receptor interaction, which helps position the P1 helix containing the $5^{\prime}$-splice site (Michel and Westhof 1990; Costa and Michel 1995). These mutations include five in P8 (U226G, A230G, A232U, A233G, and U1064G); seven in P2, P2a, or J2a/3 (A30G, A37G, U41C, A62C, $\mathrm{G} 63 \mathrm{~A}, \mathrm{~A} 65 \mathrm{U}$ and $\mathrm{A} 67 \mathrm{C})$; one in the adjoining region of $\mathrm{P} 3$, which is coaxially stacked on P8 (A222U); and one in J7/8 (U1075A). The mutation A30G at the fourth position of the L2 tetraloop, as well as mutations near the tetraloop receptor in P8 could directly affect the L2-P8 interaction. We also constructed two additional site-directed mutations at the fourth position in the L2 tetraloop (A30T and A30C) and found that both resulted in dependence on CYT-18's C-terminal domain. For both these mutants, the requirement for CYT-18's C-terminal domain was more stringent than that of the A30G mutant, with no growth detected on minimal medium with the C-terminally truncated protein (data not shown).

The remaining mutations identified in the screen were scattered in different regions of the intron, most of which are not expected to interact directly with the C-terminal domain based on structural models (Myers et al. 2002). Two mutations (U107G and G108A) are in a region of P5 that is involved in the GNRA tetraloop/receptor interaction with L9 and could potentially disrupt this critical interaction between the P4-P6 and P3-P9 domains, as could a neighboring mutations in L5 (U104C) and two mutations at the base of P9 (C1086U and A1105G). Similarly, the mutation G194U in L7.1a is expected to affect the long-range tertiary interaction P11 between L7.1a and J6a/b (Jaeger et al. 1991), as could two additional mutations in P7.1 (A185G and A201G). Another mutation (U78A) is in P4 bp- 1 at the junction of the P4-P6 stacked helices. We showed previously that mutations at this position in the $t d$ intron grossly disrupt group I intron tertiary structure (Chen et al. 2000). Finally, the remaining two mutations are in P6a (A163G) and P9.1 (U1111C).

Together, these findings suggest that CYT-18's C-terminal domain is required to suppress mutations in a variety of different regions of the intron, with many in or near nucleotide residues involved in long-range tertiary interactions that help stabilize the correct relative orientation of the P4-P6 and P3-P9 domains of the group I intron catalytic core. In general, the mutations may directly or indirectly affect the relative orientation of the P4-P6 and P3-P9 domains, or they may affect local secondary or tertiary structures that are stabilized by binding of the protein.

\section{Disruption of the L2-P8 interaction in the $t d$ intron results in dependence on CYT-18's C-terminal domain}

To investigate further the effect of specific structural mutations, we turned to the phage T4 $t d$ intron, which has been used extensively to investigate the ability of CYT-18 to rescue structural defects in the group I intron catalytic core (Mohr et al. 1992; Myers et al. 1996; Chen et al. 2000; Mohr et al. 2001; Waldsich et al. 2002). Unlike the S. cerevisiae mt LSU intron, the wild-type $t d$ intron self-splices efficiently at low $\mathrm{Mg}^{2+}$ concentration in vitro and does not require CYT18 for splicing in vivo. Thus, it appears to be unencumbered by preexisting structural defects, which could complicate analysis.

We focused first on the L2-P8 interaction, which was potentially affected by the largest number of mutations in the initial screen. In the $t d$ intron, both the L2-P8 interaction and the L9-P5 interaction analyzed below involve a GUGA tetraloop interacting with adjoining C-G and U-A base pairs in the minor groove of the stem (Fig. 4). Detailed studies of the L2-P8 interaction in the $t d$ intron indicate that the third (G24) and fourth (A25) bases of the tetraloop hydrogen bond in the minor groove with the fifth and 
A

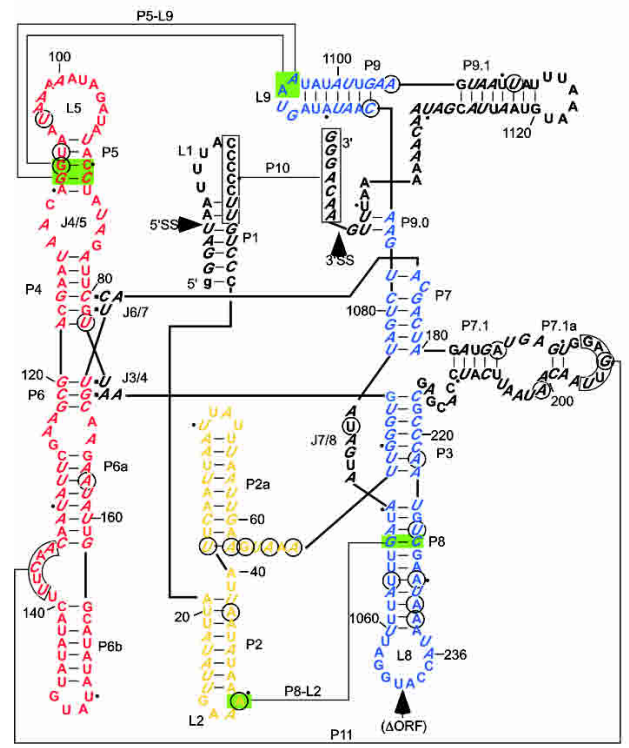

B

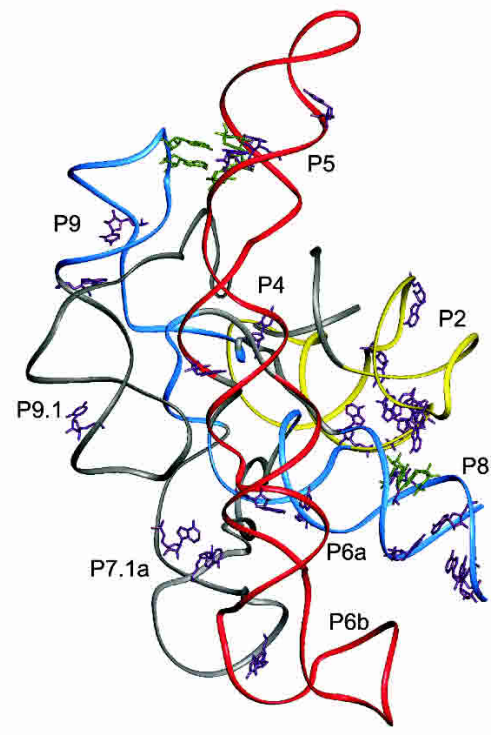

FIGURE 3. Secondary and tertiary structure models of the S. cerevisiae $\mathrm{mt}$ LSU intron showing the location of randomly selected CYT-18 C-terminal domain-dependent mutants. (A) Predicted secondary structure of the 328-nt $\triangle \mathrm{ORF}$ derivative of the S. cerevisiae mt LSU intron (GenBank accession number V00699). Nucleotide residues in the intron and exons are shown in upper- and lowercase letters, respectively, with those identical to the N. crassa mt LSU intron based on sequence alignments shown in italics. The $N$. crassa mt LSU intron has a large insertion, which disrupts the L2 tetraloop and leads to a different predicted secondary structure with a single long P2 stem (Guo and Lambowitz 1992). The $5^{\prime}$ and $3^{\prime}$ splice sites (5' SS and $3^{\prime}$ SS, respectively) are indicated by arrows, and tertiary interactions are indicated by thin connecting lines. $\triangle \mathrm{ORF}$ indicates the deleted region containing the intron ORF. Nucleotide residues at which mutations result in dependence on CYT-18's C-terminal domain for splicing are circled. Nucleotide residues involved in the L2-P8 and L9-P5 interactions are highlighted in green boxes. (B) Tertiary structure model. The model is redrawn from Jaeger et al. (1991). The intron is shown as a ribbon diagram of the phosphodiester backbone except for L1 and L8, which were not modeled. Bases that are sites of CYT-18 C-terminal domain-dependent mutations are outlined and shown in purple, and bases involved in the L2-P8 and L9-P5 tetraloop/receptor interactions are shown in green unless mutated in one of the C-terminal domain-dependent mutants. In both panels, the P4-P6 domain is shown in red, the P3-P9 domain in blue, and $\mathrm{P} 2, \mathrm{P} 2 \mathrm{a}$, and $\mathrm{J} 2 / 3$ in yellow. Other regions of the intron are shown in black.

fourth base pairs of P8 (U920-A931 and C919-G932, respectively), and they suggest an additional H-bond between the $\mathrm{O} 2$ of the second base of the tetraloop (U23) and the 2'OH of U921 (P8 base pair 6: U921-A930, Fig. 4; Costa and Michel 1995, 1997). The A25•C919-G932 interaction is a type I base triple that is relatively sequence specific with respect to the Watson-Crick base pair that serves as the acceptor, whereas the G24•U920-A931 interaction is a type II triple that appears to be somewhat less sequence specific with respect to the acceptor base pair. For both types of triples, however, all three alternative Watson-Crick base pairs are found as acceptors in natural RNAs (Doherty et al. 2001).

To analyze L2-P8 mutations, we used plasmid pTZtd1304, which contains a self-splicing 265-nt $\Delta$ ORF-derivative of the $t d$ intron (see Material and Methods), and randomized bases 3 and 4 of L2, as well as the two interacting base pairs in P8 (P8 bps-4 and -5; Fig. 4). We tested a total of 39 randomly selected mutants by using the $t d$ plating assay (Table 2). Twenty-three mutants retained splicing activity, whereas 16 mutants were unable to splice even in the presence of wild-type CYT-18 protein.

Two of the splicing-competent mutants ( 1 and 2) were phenotypically wild type and did not require CYT-18 for splicing in vivo. Both mutants retain the wild-type GUGA tetraloop and the wildtype $\mathrm{C}-\mathrm{G}$ at $\mathrm{P} 8 \mathrm{bp}-4$ but have $\mathrm{c} \cdot \mathrm{A}$ or $\mathrm{c} \cdot \mathrm{u}$ at P8 bp-5. (Note: Wild-type and mutant nucleotide residues are indicated by uppercase and lowercase letters, respectively.) Mutant 1 could conceivably form a C.A wobble base pair and retain the wild-type hydrogen bonding pattern, with the $\mathrm{H}$-bond to the ribose of the mutant $\mathrm{C}$ residue replacing that to the ribose of the wild-type $\mathrm{U}$ (Fig. 4B). Similarly, mutant 2 could retain the wild-type hydrogen bonding pattern if one assumes that the pyrimidine-pyrimidine mismatch retains $\mathrm{A}$-form helix geometry. A third splicing-competent mutant (3), which retained the wildtype GUGA with mismatches at both P8 base pairs, was spliced by the wild-type CYT-18 protein but only partially rescued by the C-terminally truncated $\Delta$ C424-669 protein.

The remaining 20 splicing-competent mutants were CYT-18 C-terminal domain dependent: They had lost the ability to self-splice and were spliced by the full-length CYT-18 protein, but not by the truncated protein lacking CYT-18's C-terminal domain. Two of these mutants (4 and 5) have mutations in L2 and no changes in $\mathrm{P} 8$, analogous to the A30G mutation in the $S$. cerevisiae $\mathrm{mt} \mathrm{LSU}$ intron (see above), whereas all but one of the others either have unchanged L2 sequences (11, 14, and 23) or at least one Watson-Crick base pair at either P8 bp-4 or bp-5. The only exception was Mutant 22, in which L2 is GUGg and P8 bps-5 and -4 are $\mathrm{u} \cdot \mathrm{u}$ and $\mathrm{a} \cdot \mathrm{G}$, respectively, both mismatches that stabilize RNA helices and could potentially support hydrogen bonding of the imino hydrogens (Wu et al. 1995).

By contrast, the remaining 16 mutants, which were unable to splice even in the presence of full-length CYT-18 protein, lack base pairs at both P8 bp-4 and P8 bp-5, and most (14/16) have helix-destabilizing mismatches at both positions (e.g., A.C, C.A, C.C, C.U, and U.C; $\mathrm{Wu}$ et al. 1995; Xia et al. 1997). The finding that mutants having these more severe structural deficiencies cannot be suppressed by CYT- 
A

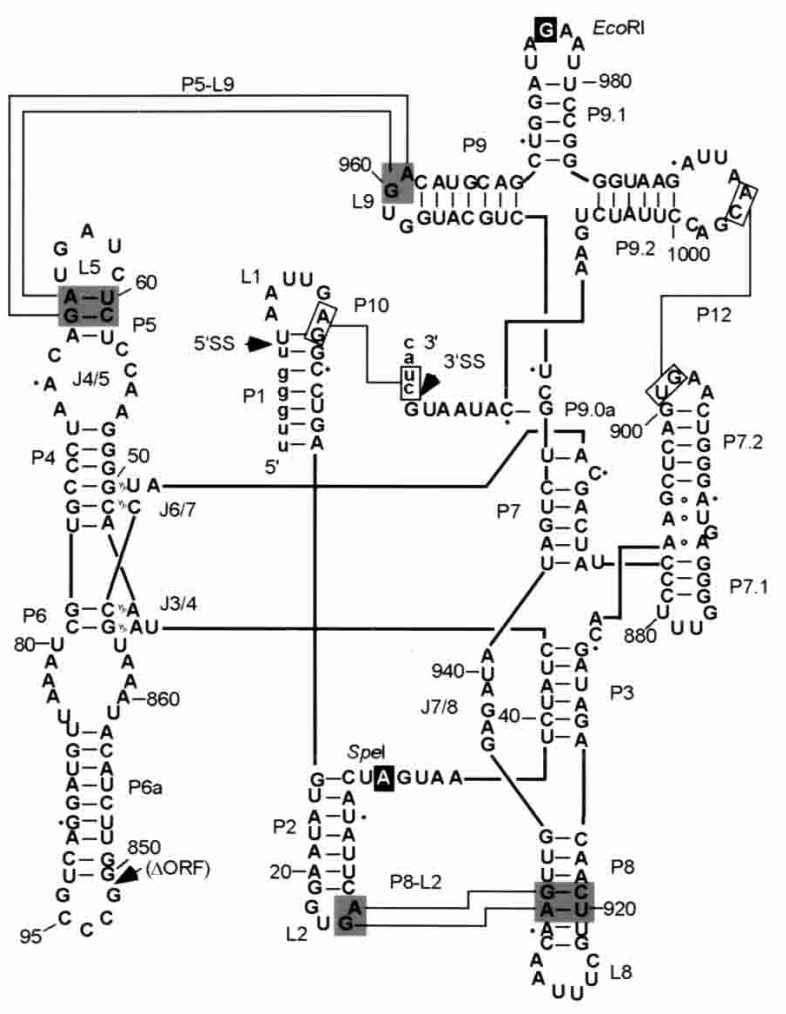

B

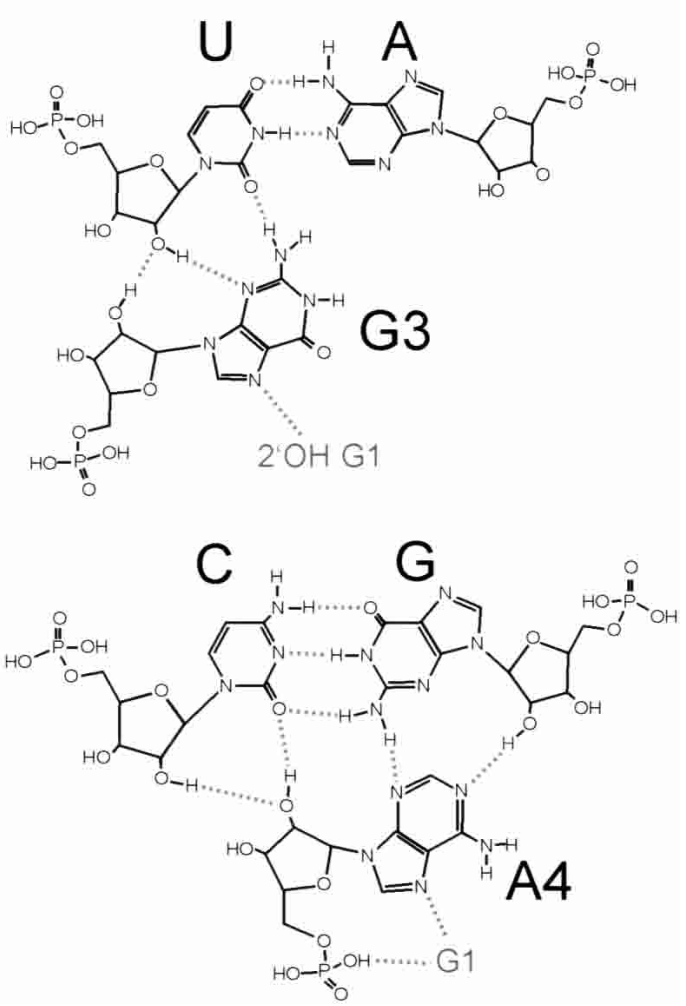

FIGURE 4. Secondary structure model of the phage T4 td- $\Delta$ ORF intron and predicted hydrogen bonding pattern for the GUGA tetraloop/ receptor interactions. (A) Predicted secondary structure of the 265-nt $\Delta$ ORF-derivative of the phage T4 $t d$ intron (GenBank accession number M12742). Abbreviations and symbols are as in Figure 3. The L2-P8 and L9-P5 interactions are highlighted in gray (Waldsich et al. 2002). Nucleotide changes that create SpeI and EcoRI sites within the intron to facilitate cloning are highlighted in black (Myers et al. 1996). (B) Predicted hydrogen bonding pattern for the GUGA tetraloop/receptor interaction in which G (loop position 3) and A (loop position 4) interact with receptor U-A and C-G base pairs, respectively. The interactions are modeled based on the X-ray crystal structures of GAAA and GUAA tetraloop/receptor interactions in the hammerhead ribozyme and the E. coli large rRNA sarcin/ricin loop (Pley et al. 1994; Correll and Swinger 2003).

18 indicates that the protein by itself is not sufficient to fix the precise spatial locations of L2 and P8 and that some nucleotide-level interaction between the two partners is still required.

\section{CYT-18's C-terminal domain is required for splicing of $t d$ introns with a disrupted L9-P5 interaction}

As indicated above, the L9-P5 interaction in the $t d$ intron is also a GUGA tetraloop/receptor interaction, which is expected to involve the third and fourth bases of the tetraloop interacting in the minor groove with P5 bps-2 and -3 (Fig. 4; Michel and Westhof 1990). To analyze this interaction, we randomized P5 bps-2 and -3 and L9 nucleotide residues 3 and 4 . In this case, we tested 34 mutants, of which 17 spliced in the presence of CYT-18 protein and 17 were nonsplicing (Table 3).

Among the 17 splicing-competent mutants, 4 could still be spliced by the C-terminally truncated CYT- 18 protein, while 13 were dependent on CYT-18's C-terminal domain. Of the four mutants spliced by the C-terminally truncated protein, only two have GNRA tetraloops, but three $(1,3$, and 4) have Watson-Crick or U-G base pairs at both P5 bps-2 and -3 , and the remaining mutant (2) has $1 \mathrm{bp}$ plus a helix stabilizing A.G mismatch at the other position. By contrast, among the $13 \mathrm{C}$-terminal domain-dependent mutants, only two (6 and 14) have base pairs at both P5 bps-2 and -3 , whereas eight retain $1 \mathrm{bp}$ at either position, with retention of $\mathrm{P} 5 \mathrm{bp}-3$ being favored, presumably because it is the terminal base pair of the short P5 stem. Only one of the C-terminal domain-dependent mutants (12) has an unchanged L9 sequence, and only five $(6,10,11,16,17)$ retain a GNRA tetraloop, which is GUaA in all cases.

As expected, the nonsplicing mutants again have more severe structural defects. Five lack Watson-Crick or G-U base pairs at both acceptor positions, none retains the wildtype L9 tetraloop, and only two (27 and 32 ) have a GNRA tetraloop. Further, several of the nonsplicing variants could form alternative pairings of the mutated sequences with sequences in J4/5 (19-26, 30-34). These findings indicate that as for L2-P8, CYT-18 is not by itself sufficient to fix the 
TABLE 2. In vivo splicing phenotypes of $t d$ intron L2-P8 mutants

\begin{tabular}{|c|c|c|c|c|c|c|}
\hline \multirow{2}{*}{\multicolumn{2}{|c|}{$\begin{array}{l}\text { Mutant } \\
\text { L2-P8 }\end{array}$}} & \multirow{2}{*}{\multicolumn{3}{|c|}{$\frac{\text { Splicing phenotype }^{\mathrm{b}}}{-\mathrm{CYT}-18+\mathrm{pA} 550^{\mathrm{c}}+\mathrm{pA} 602^{\mathrm{d}}}$}} & \multirow{2}{*}{\multicolumn{2}{|c|}{$\begin{array}{l}\text { Nonsplicing } \\
\text { td L2-P8 } \\
\text { mutants }\end{array}$}} \\
\hline & & & & & & \\
\hline WT & $\begin{array}{l}\mathrm{G} \bullet U-A \\
A \bullet C-G\end{array}$ & +++ & +++ & +++ & 24 & $\begin{array}{l}\mathrm{G} \bullet \mathrm{C} C \mathrm{C} \\
\mathrm{A} \bullet \mathrm{C} C \mathrm{C}\end{array}$ \\
\hline 1 & $\begin{array}{l}\mathrm{G} \bullet \mathrm{C} A \\
\mathrm{~A} \bullet \mathrm{C}-\mathrm{G}\end{array}$ & +++ & +++ & +++ & 25 & $\begin{array}{l}\mathrm{G} \bullet \mathrm{C} C \\
\mathrm{~A} \bullet \mathrm{C} \text { a }\end{array}$ \\
\hline 2 & $\begin{array}{l}\mathrm{G} \bullet \mathrm{C} u \\
\mathrm{~A} \bullet \mathrm{C}-\mathrm{G}\end{array}$ & +++ & +++ & +++ & 26 & $\begin{array}{l}G \bullet a \text { C } \\
A \bullet C \text { C }\end{array}$ \\
\hline 3 & $\begin{array}{l}G \bullet a g \\
A \bullet C \text { C }\end{array}$ & - & +++ & ++ & 27 & $\begin{array}{l}\mathrm{G} \bullet \mathrm{c} u \\
\mathrm{~A} \bullet \mathrm{C} \mathrm{a}\end{array}$ \\
\hline 4 & $\begin{array}{l}\mathrm{G} \bullet U-\mathrm{A} \\
\mathrm{g} \bullet \mathrm{C}-\mathrm{G}\end{array}$ & - & +++ & - & 28 & $\begin{array}{ll}\mathrm{c} \bullet \mathrm{C} & \mathrm{C} \\
\mathrm{g} \bullet \mathrm{u} & \mathrm{C}\end{array}$ \\
\hline 5 & $\begin{array}{l}\mathrm{c} \bullet U-A \\
\mathrm{~g} \bullet \mathrm{C}-\mathrm{G}\end{array}$ & - & +++ & - & 29 & $\begin{array}{ll}c \bullet C & A \\
g \bullet u \quad c\end{array}$ \\
\hline 6 & $\begin{array}{l}\mathrm{G} \bullet \mathrm{U} u \\
\mathrm{~g} \bullet \mathrm{C}-\mathrm{G}\end{array}$ & - & +++ & - & 30 & $\begin{array}{l}\mathrm{C}^{\bullet} \mathrm{C} \\
\mathrm{g} \bullet \mathrm{C}\end{array}$ \\
\hline 7 & $\begin{array}{l}\mathrm{G} \bullet \mathrm{a} \mathrm{c} \\
\mathrm{g} \bullet \mathrm{C}-\mathrm{G}\end{array}$ & - & +++ & - & 31 & $\begin{array}{l}\mathrm{G} \bullet U \mathrm{c} \\
\mathrm{g} \bullet \mathrm{u} u\end{array}$ \\
\hline 8 & $\begin{array}{l}c \bullet a c c \\
g \bullet C-G\end{array}$ & - & +++ & - & 32 & $\begin{array}{l}\mathrm{G} \bullet \mathrm{c} C \\
\mathrm{~g} \bullet \mathrm{u} \quad \mathrm{c}\end{array}$ \\
\hline 9 & $\begin{array}{l}u \bullet g g \\
g \bullet C-G\end{array}$ & - & +++ & - & 33 & $\begin{array}{l}\mathrm{G} \bullet \mathrm{c} C \\
\mathrm{~g} \bullet \mathrm{a} \quad \mathrm{C}\end{array}$ \\
\hline 10 & $\begin{array}{l}G \bullet \text { g-c } \\
g \bullet u \text { c }\end{array}$ & - & +++ & - & 34 & $\begin{array}{l}\mathrm{G} \bullet \mathrm{C} C \\
\mathrm{~g} \bullet \mathrm{C} \quad \mathrm{C}\end{array}$ \\
\hline 11 & $\begin{array}{l}G \bullet a c \\
A \bullet g a\end{array}$ & - & +++ & - & 35 & $\begin{array}{l}G \bullet g A \\
g \bullet C \quad C\end{array}$ \\
\hline 12 & $\begin{array}{l}\mathrm{c} \bullet \mathrm{a}-\mathrm{u} \\
\mathrm{g} \bullet \mathrm{C} \mathrm{c}\end{array}$ & - & +++ & - & 36 & $\begin{array}{l}\mathrm{G} \bullet \mathrm{c} A \\
\mathrm{~g} \bullet \mathrm{C} \text { a }\end{array}$ \\
\hline 13 & $\begin{array}{l}G \bullet a \mathrm{~g} \\
\mathrm{~g} \bullet \mathrm{g}-\mathrm{c}\end{array}$ & - & ++ & - & 37 & $\begin{array}{l}G \bullet a \quad c \\
g \bullet C \text { a }\end{array}$ \\
\hline 14 & $\begin{array}{l}G \cdot a A \\
A \bullet g-u\end{array}$ & - & ++ & - & 38 & $\begin{array}{l}\mathrm{G} \bullet \mathrm{C} u \\
\mathrm{~g} \bullet \mathrm{C} u\end{array}$ \\
\hline 15 & $\begin{array}{l}\mathrm{G} \bullet \mathrm{c} A \\
\mathrm{~g} \bullet \mathrm{u}-\mathrm{a}\end{array}$ & - & ++ & - & 39 & $\begin{array}{l}G \bullet C \quad u \\
g \bullet C \quad c\end{array}$ \\
\hline 16 & $\begin{array}{l}\mathrm{G} \bullet \mathrm{g}-\mathrm{C} \\
\mathrm{g} \bullet \mathrm{C} \mathrm{c}\end{array}$ & - & ++ & - & & \\
\hline 17 & $\begin{array}{l}G \cdot a-u \\
g \bullet u ~ u\end{array}$ & - & + & - & & \\
\hline 18 & $\begin{array}{l}G \bullet a-u \\
g \bullet u c\end{array}$ & - & + & - & & \\
\hline 19 & $\begin{array}{l}G \bullet a-u \\
g \bullet g a\end{array}$ & - & + & - & & \\
\hline 20 & $\begin{array}{l}G \bullet g-C \\
g \bullet g G\end{array}$ & - & + & - & & \\
\hline 21 & $\begin{array}{l}\mathrm{G} \bullet \mathrm{a} g \\
\mathrm{~g} \bullet \mathrm{C}-\mathrm{G}\end{array}$ & - & + & - & & \\
\hline 22 & $\begin{array}{l}\mathrm{G} \bullet \mathrm{U} u \\
\mathrm{~g} \bullet \mathrm{a} G\end{array}$ & - & + & - & & \\
\hline 23 & $\begin{array}{l}\mathrm{G} \bullet \mathrm{C} A \\
\mathrm{~A} \bullet \mathrm{C} C \mathrm{C}\end{array}$ & - & + & - & & \\
\hline
\end{tabular}

${ }^{\mathrm{a}}$ Mutants are indicated by number along with the sequences of L2 nt 3 (top) and 4 (bottom) and P8 bp 5 (top) and 4 (bottom). Uppercase letters indicate wild-type nucleotide residues, and lowercase letters indicate mutations.

${ }^{b}$ Splicing phenotypes are defined as described in Materials and Methods, based on at least two repeats of the $t d$ plating assay for each mutant.

${ }^{c}$ pA550 expresses full-length CYT-18 protein.

dpA602 expresses C-terminally truncated CYT-18 protein. correct spatial positions of L9 and P5 and that at least some nucleotide-level interaction is still required.

\section{DISCUSSION}

Together, our results for two different group I introns show that CYT-18's C-terminal domain is required to suppress a variety of different structural mutations including those affecting two long-range GNRA tetraloop/receptor interactions: L2-P8, which helps position the P1 helix containing the $5^{\prime}$ splice site, and L9-P5, a key tertiary interaction that helps establish the correct relative orientation of the P4-P6 and P3-P9 domains of the catalytic core (Michel and Westhof 1990; Costa and Michel 1995). Our results indicate that different structural mutations in group I introns can result in dependence on different regions of CYT-18 for RNA splicing.

The simplest interpretation of our results is that the suppression of some intron RNA mutations by CYT-18 requires additional, direct contacts with the C-terminal domain, whereas the suppression of other mutations does not require such contacts. The possibility that the inability to suppress some mutations reflects reduced amounts of active C-terminally truncated protein in vivo is unlikely, because previous colony Westerns showed that the amount of soluble C-terminally truncated CYT-18 is equal to that of the wild-type protein under the conditions of the $t d$ plating assays (Mohr et al. 1992) and this protein is fully active in tyrosyl-adenylation assays (Mohr et al. 2001). Further, although the unbound C-terminally truncated protein is unstable when incubated at $37^{\circ} \mathrm{C}$ in vitro, complicating biochemical analysis (Mohr et al. 2001), $\mathrm{k}_{\text {off }}$ assays showed that the diluted protein intially forms the same amount of heparin-stable compex as the wild-type protein with three different group I introns tested $(t d, \omega$, and the Tetrahymena thermophila $\triangle \mathrm{P} 5 \mathrm{abc}$ intron; G. Mohr and A.M. Lambowitz, data not shown). The C-terminal domain of bacterial TyrRSs is attached to the remainder of the protein via a flexible linker and does not interact strongly with other regions of the protein (Guez et al. 2000; Yaremchuk et al. 2002). Thus, it is also unlikely that the absence of the Cterminal domain has a major effect on the structure of other regions of CYT-18.

Analysis of random mutations in L2-P8 and L9-P5 in the $t d$ intron showed that a high proportion of the mutations weakening these interactions result in dependence on CYT18's C-terminal domain, but a few CYT-18-dependent variants do not require the C-terminal domain, and a substantial proportion cannot be suppressed even by the wild-type CYT-18 protein. These different splicing phenotypes presumably reflect both different degrees of disruption of the original interaction and alternative interactions that may be possible in different mutants. The finding that some mutants in both L2-P8 and L9-P5 cannot be suppressed by the wild-type CYT-18 protein indicates that the protein by itself is not sufficient to fix the correct positions of the interacting 
TABLE 3. In vivo splicing phenotypes of $t d$ intron L9-P5 mutants

\begin{tabular}{|c|c|c|c|c|c|c|}
\hline \multirow{2}{*}{\multicolumn{2}{|c|}{$\begin{array}{l}\text { Mutant } \\
\text { L9-P5 }\end{array}$}} & \multirow{2}{*}{\multicolumn{3}{|c|}{$\frac{\text { Splicing phenotype }^{\mathrm{b}}}{-\mathrm{CYT}-18+\mathrm{pA} 550^{\mathrm{c}}+\mathrm{pA} 602^{\mathrm{d}}}$}} & \multirow{2}{*}{\multicolumn{2}{|c|}{$\begin{array}{l}\text { Nonsplicing } \\
t d \text { L9-P5 } \\
\text { mutants }\end{array}$}} \\
\hline & & & & & & \\
\hline WT & $\begin{array}{l}\mathrm{G} \bullet U-\mathrm{A} \\
\mathrm{A} \bullet \mathrm{C}-\mathrm{G}\end{array}$ & +++ & +++ & +++ & 18 & $\begin{array}{l}c \bullet a A \\
g \bullet u ~ u\end{array}$ \\
\hline 1 & $\begin{array}{l}a \bullet g-u \\
A \bullet u-G\end{array}$ & - & +++ & +++ & 19 & $\begin{array}{l}a \cdot g-u \\
c \bullet u u\end{array}$ \\
\hline 2 & $\begin{array}{l}\mathrm{a} \bullet \mathrm{a} g \\
\mathrm{~g} \bullet \mathrm{C}-\mathrm{G}\end{array}$ & - & +++ & +++ & 20 & $\begin{array}{l}\mathrm{a} \bullet \mathrm{U} u \\
\mathrm{c} \bullet \mathrm{g} \mathrm{G}\end{array}$ \\
\hline 3 & $\begin{array}{l}\mathrm{C} \bullet U-\mathrm{g} \\
\mathrm{A} \bullet \mathrm{C}-\mathrm{G}\end{array}$ & - & +++ & ++ & 21 & $\begin{array}{l}\mathrm{C} \bullet U \mathrm{U} \\
\mathrm{A} \bullet \mathrm{u} u\end{array}$ \\
\hline 4 & $\begin{array}{l}\mathrm{a} \bullet U-\mathrm{g} \\
\mathrm{A} \cdot \mathrm{g}-\mathrm{C}\end{array}$ & - & ++ & ++ & 22 & $\begin{array}{l}c \bullet U \mathrm{u} \\
\mathrm{c} \bullet \mathrm{u} \mathrm{u}\end{array}$ \\
\hline 5 & $\begin{array}{l}\mathrm{C} \bullet \mathrm{U} u \\
\mathrm{~A} \bullet \mathrm{C}-\mathrm{G}\end{array}$ & - & +++ & - & 23 & $\begin{array}{l}\mathrm{G} \bullet \mathrm{g}-\mathrm{C} \\
\mathrm{c} \bullet \mathrm{u} \mathrm{C}\end{array}$ \\
\hline 6 & $\begin{array}{l}a \cdot g-c \\
A \bullet g-c\end{array}$ & - & ++ & - & 24 & $\begin{array}{l}\mathrm{G} \bullet \mathrm{c} u \\
\mathrm{c} \bullet \mathrm{u} u\end{array}$ \\
\hline 7 & $\begin{array}{l}\mathrm{G} \bullet \mathrm{c}-\mathrm{g} \\
\mathrm{u} \bullet \mathrm{u} \mathrm{u}\end{array}$ & - & ++ & - & 25 & $\begin{array}{l}\mathrm{a} \bullet \mathrm{U} u \\
\mathrm{c} \bullet \mathrm{g}-\mathrm{u}\end{array}$ \\
\hline 8 & $\begin{array}{l}a \bullet c-g \\
c \bullet u ~ u\end{array}$ & - & ++ & - & 26 & $\begin{array}{l}a \cdot U-g \\
u \cdot g-u\end{array}$ \\
\hline 9 & $\begin{array}{l}a \cdot g-c \\
g \bullet u u\end{array}$ & - & ++ & - & 27 & $\begin{array}{l}a \bullet g \text { g } \\
A \bullet g-u\end{array}$ \\
\hline 10 & $\begin{array}{l}\mathrm{a} \bullet \mathrm{g}-\mathrm{c} \\
\mathrm{A} \bullet \mathrm{u} u\end{array}$ & - & ++ & - & 28 & $\begin{array}{l}\mathrm{c} \bullet \mathrm{c}-\mathrm{g} \\
\mathrm{g} \bullet \mathrm{C} \mathrm{u}\end{array}$ \\
\hline 11 & $\begin{array}{l}\mathrm{a} \bullet \mathrm{U} u \\
\mathrm{~A} \cdot \mathrm{a}-\mathrm{u}\end{array}$ & - & ++ & - & 29 & $\begin{array}{l}a \bullet g-c \\
c \bullet a ~ a ~\end{array}$ \\
\hline 12 & $\begin{array}{l}G \bullet a c \\
A \bullet g G\end{array}$ & - & ++ & - & 30 & $\begin{array}{l}a \bullet c u \\
c \bullet a-u\end{array}$ \\
\hline 13 & $\begin{array}{l}a \bullet g g \\
u \bullet u ~ u\end{array}$ & - & ++ & - & 31 & $\begin{array}{l}a \cdot g-u \\
g \bullet g-u\end{array}$ \\
\hline 14 & $\begin{array}{l}a \cdot g-u \\
g \bullet a-u\end{array}$ & - & + & - & 32 & $\begin{array}{l}\mathrm{a} \bullet \mathrm{c} u \\
\mathrm{~A} \bullet \mathrm{g}-\mathrm{u}\end{array}$ \\
\hline 15 & $\begin{array}{l}\mathrm{G} \bullet \mathrm{c}-\mathrm{g} \\
\mathrm{c} \bullet \mathrm{u} \mathrm{u}\end{array}$ & - & + & - & 33 & $\begin{array}{l}c \bullet U-g \\
c \bullet u ~ u\end{array}$ \\
\hline 16 & $\begin{array}{l}a \cdot g-u \\
A \bullet u u\end{array}$ & - & + & - & 34 & $\begin{array}{l}\mathrm{a} \bullet U-\mathrm{g} \\
\mathrm{g} \bullet \mathrm{u} \mathrm{u}\end{array}$ \\
\hline 17 & $\begin{array}{l}\mathrm{a} \bullet \mathrm{U} u \\
\mathrm{~A} \bullet \mathrm{u} u\end{array}$ & - & + & - & & \\
\hline
\end{tabular}

${ }^{a}$ Mutants are indicated by number along with the sequences of $L 9$ nt 3 (top) and 4 (bottom) and P5 bp 3 (top) and 2 (bottom). Uppercase letters indicate wild-type nucleotide residues, and lowercase letters indicate mutations.

${ }^{\mathrm{b}}$ Splicing phenotypes are defined as described in Materials and Methods, based on at least two repeats of the $t d$ plating assay for each mutant.

${ }^{c}$ pA550 expresses full-length CYT-18 protein.

${ }^{d}$ pA602 expresses C-terminally truncated CYT-18 protein.

partners and that some nucleotide-level interaction is still required.

The L9-P5 and L2-P8 interactions occur at opposite ends of the intron RNA, which interact with different regions of the CYT-18 protein. Our results do not distinguish whether CYT-18's C-terminal domain stabilizes these interactions directly or indirectly by stabilizing other RNA secondary or tertiary structures that then either stabilize or compensate for the weakened interaction. According to structural models, CYT-18's C-terminal domain is in proximity to and could interact directly with P2 and P8 on the side opposite that which binds the P1 helix, possibly contributing to the large number of C-terminal domain-dependent mutants in or near these regions of the S. cerevisiae mt LSU intron. By contrast, CYT-18's C-terminal domain does not appear to be in proximity to $\mathrm{P} 5$ and $\mathrm{P}$, which interact instead with the nucleotide-binding fold domain (Myers et al. 2002). Thus, the requirement for CYT-18's C-terminal domain to suppress L9-P5 mutations may reflect that it acts elsewhere to clamp the relative position of the P4-P6 and P3-P9 domains, compensating for weakened interactions between L9 and P5. However, because the C-terminal domain is attached by a flexible hinge, we cannot exclude the possibility that it interacts directly with L9-P5 in a different configuration than that assumed in the model (see data and discussion in Myers et al. 2002).

Finally, we suggested previously that group I introns were originally self-splicing and became dependent on proteins as a result of structural mutations that impair self-splicing (Lambowitz and Perlman 1990). Our results support the hypothesis that different group I introns form similar complexes with CYT-18 involving all three protein domains and that dependence on CYT-18's C-terminal domain reflects primarily different structural mutations in different introns (see Introduction). Both the N. crassa mt LSU and ND1 introns appear to have appropriate L9-P5 tetraloop/receptor interactions (mt LSU: G・U-A and A $\cdot \mathrm{C}-\mathrm{G} ; \mathrm{ND1}: \mathrm{A} \cdot \mathrm{C}-\mathrm{G}$ and $A \cdot C-G$ ), which are the same as the L9-P5 interactions in the $t d$ and $S$. cerevisiae $\mathrm{mt}$ LSU introns, respectively. However, the N. crassa mt LSU intron has a large insertion, which disrupts the L2 tetraloop and could be a relatively recent mutation that contributes to dependence on CYT18's C-terminal domain. By contrast, the ND1 intron lacks P2 and may compensate for this deficiency and fewer interactions with the CYT-18 C-terminal domain by greater dependence on other RNA-RNA or RNA-protein interactions, for example, with CYT-18's nucleotide-binding fold domain. Indeed, a mutant CYT-18 protein with a deletion in the $\mathrm{H} 0$ helix at the $\mathrm{N}$ terminus of the protein was unable to bind or splice the ND1 intron, but retained substantial splicing activity with the mt LSU intron (Mohr et al. 2001). Thus, although CYT-18 recognizes common conserved structural features of group I introns, it has evolved to function in splicing structurally diverse group I introns in somewhat different ways.

\section{MATERIALS AND METHODS}

\section{E. coli strains and growth media}

E. coli strain 1904, a thyA ::kan ${ }^{\mathrm{R}}$ derivative of C600, was used for $t d$ plating assays (Belfort et al. 1983) and DH5 $\alpha$ was used for 
cloning. Bacteria were grown in LB or minimal medium supplemented as required with thymine $(50 \mu \mathrm{g} / \mathrm{mL})$, ampicillin $(100$ $\mu \mathrm{g} / \mathrm{mL})$, chloramphenicol $(25 \mu \mathrm{g} / \mathrm{mL})$, kanamycin $(40 \mu \mathrm{g} / \mathrm{mL})$, or trimethoprim $(20 \mu \mathrm{g} / \mathrm{mL})$. For $t d$ plating assays, minimal medium was supplemented with $0.1 \%$ Norit A-treated casamino acids and $0.2 \%$ glucose (Belfort et al. 1983).

\section{Recombinant plasmids}

Plasmid pA550, which expresses the wild-type CYT-18 protein, and pA602, which expresses the C-terminal truncation mutant $\Delta$ C424-669, have been described (Mohr et al. 1992; Myers et al. 1996; Mohr et al. 2001). Both the wild-type and $\Delta C 424-669$ proteins have the $\mathrm{N}$-terminal $\mathrm{mt}$ import sequence (amino acid residues 1-31) replaced by an ATG codon, and $\Delta C 424-669$ has a TAA stop codon after codon 423 (Kittle Jr. et al. 1991).

Plasmid pTZtd1304 contains a 265-nt $\Delta$ ORF derivative of the phage T4 $t d$ intron cloned behind the lac promoter in pTZ18U, a ColE1-origin plasmid containing an $a m p^{\mathrm{R}}$ marker (USB Biochemicals; Myers et al. 1996). The intron contains two nucleotide changes in nonessential regions that introduce SpeI and EcoRI sites to facilitate the construction of mutant introns.

Plasmid pUTD contains an intronless phage T4 $t d$ gene cloned behind the lac promoter in pUC8. It was constructed by PCR amplifying $5^{\prime}$ and $3^{\prime}$ segments of the $t d$ gene from pTZtd1493 (gift of Marlene Belfort, Wadsworth Center, Albany, NY) to introduce a polylinker at the junction between the two segments. The $5^{\prime}$ segment (codons $1-117)$ was amplified with primers tdNde $\left(5^{\prime}\right.$ TATACATATGAAACAATACCAAGAT), which adds an NdeI site upstream of the $t d$ ATG codon, and td1 (5'-AAACCGGTACCA AAATCACGCCA), which adds KpnI and AgeI sites after codon 117. The 3' segment (codons 118-292) was amplified with primers Forward (5'-CTGCAGGATATCTGGATCCAC) and td2 (5'AAACCGGTGCTAGCCTCGAGGGTGTAGACCAATT), which adds an 18-nt polylinker containing AgeI, NheI, and XhoI sites, between codons 117 and 118 . This region corresponds to a surface loop in the X-ray crystal structures of the Lactococcus lactis and phage T4 thymidylate synthases and is of variable length in different thymidylate synthases (Hardy et al. 1987; Finer-Moore et al. 1994). The products of the first and second PCRs were digested with NdeI + AgeI and AgeI + HindIII, respectively, gel-purified, and ligated together into pET3a digested with NdeI + HindIII to yield the intermediate construct pETD. A DNA fragment containing the modified $t d$ gene from pETD was then excised with BglII + PstI, gel-purified, and cloned between the BamHI and PstI sites of pUC8 to give pUTD. We confirmed that the modified $t d$ gene in pUTD complements the thy $A^{-}$phenotype of $E$. coli strain 1904 as efficiently as the wild-type $t d$ gene in the parent construct pTZtd1493 (data not shown).

pUTDW and pUTDW $\Delta$ ORF contain the full-length (1154 nt) and $\Delta \mathrm{ORF}$ (328 nt) S. cerevisiae mt LSU introns, respectively, inserted along with short flanking exons in the intronless $t d$ gene in pUTD. To construct pUTDW, the $S$. cerevisiae $\mathrm{mt}$ LSU intron (1154 nt) along with flanking $5^{\prime}$ - and $3^{\prime}$-exon sequences (5 and 7 $\mathrm{nt}$, respectively) was amplified from pBS $\omega$ (gift of Dr. Peter Zassenhaus, St. Louis University) with primers tdScl (5'-TTTGGTA CCGGGATAATTTACCCCC), which adds a KpnI site, and tdSc2 (5'-ACCCTCGAGCCCTGTTCAAATTTTTTG), which adds an Xhol site. The PCR product was then cloned between the corresponding sites of pUTD to give pUTDW. pUTDW $\triangle$ ORF was con- structed similarly by amplifying a 236-nt $5^{\prime}$ segment of the intron with $\operatorname{tdScl}$ (see above) and $\operatorname{tdSc} \Delta 5$ (5'-ATGCCATGGTATTT ATTCGACATTGGG) and an 86-nt $3^{\prime}$ segment with $\operatorname{tdSc} \Delta 3$ (5'ATGCCATGGATTTTATTTGATAATGATAT) and tdSc2 (see above), thereby replacing the ORF in L8 with an NcoI site. All constructs were verified by sequencing.

\section{Random mutagenesis of the $S$. cerevisiae mt LSU intron}

Libraries of S. cerevisiae mt LSU introns containing random mutations were constructed in pUTDWDORF by error-prone PCR (Fromant et al. 1995) in $100 \mu \mathrm{L}$ of reaction medium containing 5 units of Taq polymerase (Life Technologies), $20 \mathrm{ng}$ pUTDW $\Delta$ ORF template, $1 \mu \mathrm{M}$ each of the primers tdSc1 and tdSc2 (see above), $20 \mathrm{mM}$ Tris- $\mathrm{HCl}(\mathrm{pH} \mathrm{8.4)}, 50 \mathrm{mM} \mathrm{KCl}, 1 \mathrm{mM} \mathrm{dCTP}$ and dTTP, $0.2 \mathrm{mM}$ dATP and dGTP, $6.5 \mathrm{mM} \mathrm{MgCl}_{2}$, and $0.5 \mathrm{mM} \mathrm{MnCl}_{2}$. The reaction was done in a Perkin-Elmer Gene Amp PCR System 2400 for 30 cycles of $94^{\circ} \mathrm{C}$ for $30 \mathrm{sec}, 55^{\circ} \mathrm{C}$ for $30 \mathrm{sec}$ and $72^{\circ} \mathrm{C}$ for $1 \mathrm{~min}$, with a 10 -min extension at the end of the last cycle. The PCR products were cleaved with KpnI + XhoI, gel-purified, and cloned between the KpnI and XhoI sites of pUTDWDORF.

\section{Construction of $t d$ intron mutants}

To construct L2-P8 mutants, two segments of the $t d$ intron were amplified separately by PCR of pTZtd1304 (Myers et al. 1996). The first PCR used primers TD30F (5'-GGTTATGAAACCGATGAT CG) and TDL2R (5'-GCGACTAGTATAAGNNACCTTATACTC), which introduces random nucleotide residues at positions 24 and 25 of L2, and the second PCR used primers TD30F and TDP8R (5'-GGGGGAATTCTATCCAGCTGCATGTCACCATGC AGAGCAGACTATATCTCCAANNTGTTAAAGCANNTTGTCT ATCG), which introduces random nucleotide residues at P8 bps-4 and -5. ("N" denotes a position synthesized with equimolar concentrations of all four dNTPs.) The products of the two PCRs were digested with StyI + SpeI, and SpeI + EcoRI, respectively, purified in a $1 \%$ agarose gel, and ligated together into pTZtd1304 digested with StyI + EcoRI.

To construct the L9-P5 mutants, PCR was carried out using pTZtd 1304 as template with primer TDP5N (5'-ACTTATACTA GTAATCTATCTAAACGGGGAACCTNNCTAGTNNACAATC), which introduces random nucleotide residues in P5 bps-2 and -3, and primer TDL9N (5'-CCCGGAATTCTATCCAGCTGCATGN NACCATGCAGAG), which introduces random nucleotide residues at the third and fourth positions in L9. The PCR product was digested with EcoRI + SpeI, purified in a $1 \%$ agarose gel, and cloned between corresponding sites of pTZtd1304.

All PCR-amplified regions were sequenced completely to insure that no adventitious mutations had been introduced.

\section{E. coli genetic assay of CYT-18-dependent group I intron splicing}

Splicing phenotypes were determined by $t d$ plating assays as described (Mohr et al. 1992; Myers et al. 1996; Chen et al. 2000). E. coli strain 1904 thyA:: $\mathrm{kan}^{\mathrm{R}}$ was cotransformed with a plasmid harboring the phage $\mathrm{T} 4 t d$ gene disrupted by group I intron and a 
plasmid expressing wild-type or mutant CYT-18 protein or the vector pACYC184. Cells were plated on LB medium supplemented with thymine plus ampicillin, chloramphenicol, and kanamycin, and individual colonies were picked, inoculated into liquid cultures containing the same medium, and grown overnight at $37^{\circ} \mathrm{C}$. Aliquots were then plated on MM (minimal medium supplemented with $0.1 \%$ Norit A-treated casamino acids and $0.2 \%$ glucose; Belfort et al. 1983), MMT (MM supplemented with thymine), or TTM (MM supplemented with thymine and trimethoprim) and incubated at $37^{\circ} \mathrm{C}$ overnight. Growth phenotypes are categorized as follows: +++ , growth on MM equals MMT and no growth on TTM; ++, growth on MM equals MMT and incomplete inhibition on TTM; +, slow growth on MM and no inhibition on TTM; -, no growth on MM and growth on TTM equals MMT.

To isolate CYT-18 C-terminal domain-dependent mutants of the $S$. cerevisiae $\mathrm{mt}$ LSU intron, pTDW $\Delta \mathrm{ORF}$ containing the intron with random mutations introduced by mutagenic PCR (see above) was cotransformed into E. coli 1904 with pA602, which expresses the C-terminally truncated CYT-18 protein. Cotransformants were selected by plating on LB plus thymine plates containing ampicillin and chloramphenicol and then replated on $\mathrm{MM}$, MMT, and TTM. Those that had a $\mathrm{Td}^{-}$phenotype (i.e., failed to grow on MM, but grew well on MMT and TTM) or weak $\mathrm{Td}^{+}$ phenotype (i.e., grew weakly on MM, but much better on MMT and TTM) were picked for plasmid preparation. The reisolated plasmids containing mutant introns were transformed into E. coli 1904 containing either pA550, which expresses the wild-type CYT18 protein, pA602, or the vector pACYC184 and tested again by plating on MM, MMT, and TTM. Mutants that grew better on $\mathrm{MM}$ in the presence of pA550 than in the presence of pA602 were classified as CYT-18 C-terminal domain-dependent mutants and were sequenced with the primer TDSEQ1 (5'-AGGATAC CATAGCGGT) to identify the mutations.

\section{ACKNOWLEDGMENTS}

We thank Paul Paukstelis for comments on the manuscript. This work was supported by NIH grant GM37951.

The publication costs of this article were defrayed in part by payment of page charges. This article must therefore be hereby marked "advertisement" in accordance with 18 USC section 1734 solely to indicate this fact.

Received October 20, 2003; accepted December 18, 2003.

\section{REFERENCES}

Akins, R.A. and Lambowitz, A.M. 1987. A protein required for splicing group I introns in Neurospora mitochondria is mitochondrial tyrosyl-tRNA synthetase or a derivative thereof. Cell 50: 331-345.

Belfort, M., Moelleken, A., Maley, G.F., and Maley, F. 1983. Purification and properties of T4 phage thymidylate synthetase produced by the cloned gene in an amplification vector. J. Biol. Chem. 258: 2045-2051.

Brick, P., Bhat, T.N., and Blow, D.M. 1989. Structure of tyrosyl-tRNA synthetase refined at $2.3 \AA$ resolution. Interaction of the enzyme with the tyrosyl adenylate intermediate. J. Mol. Biol. 208: 83-98.

Caprara, M.G., Lehnert, V., Lambowitz, A.M., and Westhof, E. 1996a. A tyrosyl-tRNA synthetase recognizes a conserved tRNA-like structural motif in the group I intron catalytic core. Cell 87: 1135-1145.
Caprara, M.G., Mohr, G., and Lambowitz, A.M. 1996b. A tyrosyltRNA synthetase protein induces tertiary folding of the group I intron catalytic core. J. Mol. Biol. 257: 521-531.

Cech, T.R. 1993. Catalytic RNA: Structure and mechanism. Biochem. Soc. Trans. 21: 229-234.

Chen, X., Gutell, R.R., and Lambowitz, A.M. 2000. Function of tyrosyl-tRNA synthetase in splicing group I introns: An induced-fit model for binding to the P4-P6 domain based on analysis of mutations at the junction of the P4-P6 stacked helices. J. Mol. Biol. 301: 265-283.

Cherniack, A.D., Garriga, G., Kittle Jr., J.D., Akins, R.A., and Lambowitz, A.M. 1990. Function of Neurospora mitochondrial tyrosyltRNA synthetase in RNA splicing requires an idiosyncratic domain not found in other synthetases. Cell 62: 745-755.

Correll, C.C. and Swinger, K. 2003. Common and distinctive features of GNRA tetraloops based on a GUAA tetraloop structure at $1.4 \AA$ resolution. RNA 9: 355-363.

Costa, M. and Michel, F. 1995. Frequent use of the same tertiary motif by self-folding RNAs. EMBO J. 14: 1276-1285.

. 1997. Rules for RNA recognition of GNRA tetraloops deduced by in vitro selection: Comparison with in vivo evolution. EMBO J. 16: 3289-3302.

Doherty, E.A., Batey, R.T., Masquida, B., and Doudna, J.A. 2001. A universal mode of helix packing in RNA. Nat. Struct. Biol. 8: 339343.

Finer-Moore, J.S., Maley, G.F., Maley, F., Montfort, W.R., and Stroud, R.M. 1994. Crystal structure of thymidylate synthase from T4 phage: Component of a deoxynucleoside triphosphate-synthesizing complex. Biochemistry 33: 15459-15468.

Fromant, M., Blanquet, S., and Plateau, P. 1995. Direct random mutagenesis of gene-sized DNA fragments using polymerase chain reaction. Anal. Biochem. 224: 347-353.

Golden, B.L., Gooding A.R., Podell E.R., and Cech T.R. 1998. A preorganized active site in the crystal structure of the Tetrahymena ribozyme. Science 282: 259-264.

Guez, V., Nair, S., Chaffotte, A., and Bedouelle, H. 2000. The anticodon-binding domain of tyrosyl-tRNA synthetase: State of folding and origin of the crystallographic disorder. Biochemistry 39: 17391747.

Guo, Q. and Lambowitz, A.M. 1992. A tyrosyl-tRNA synthetase binds specifically to the group I intron catalytic core. Genes \& Dev. 6: $1357-1372$.

Hardy, L.W., Finer-Moore, J.S., Montfort, W.R., Jones, M.O., Santi, D.V., and Stroud, R.M. 1987. Atomic structure of thymidylate synthase: Target for rational drug design. Science 235: 448-455.

Jaeger, L., Westhof, E., and Michel, F. 1991. Function of P11, a tertiary base pairing in self-splicing introns of subgroup IA. J. Mol. Biol. 221: 1153-1164.

Kämper, U., Kück, U., Cherniack, A.D., and Lambowitz, A.M. 1992. The mitochondrial tyrosyl-tRNA synthetase of Podospora anserina is a bifunctional enzyme active in protein synthesis and RNA splicing. Mol. Cell. Biol. 12: 499-511.

Kittle Jr., J.D., Mohr, G., Gianelos, J.A., Wang, H., and Lambowitz, A.M. 1991. The Neurospora mitochondrial tyrosyl-tRNA synthetase is sufficient for group I intron splicing in vitro and uses the carboxy-terminal tRNA-binding domain along with other regions. Genes \& Dev. 5: 1009-1021.

Lambowitz, A.M. and Perlman, P.S. 1990. Involvement of aminoacyltRNA synthetases and other proteins in group I and group II intron splicing. Trends Biochem. Sci. 15: 440-444.

Michel, F. and Westhof, E. 1990. Modelling of the three-dimensional architecture of group I catalytic introns based on comparative sequence analysis. J. Mol. Biol. 216: 585-610.

Mohr, G., Zhang, A., Gianelos, J.A., Belfort, M., and Lambowitz, A.M. 1992. The Neurospora CYT-18 protein suppresses defects in the phage T4 $t d$ intron by stabilizing the catalytically active structure of the intron core. Cell 69: 483-494.

Mohr, G., Rennard, R., Cherniack, A.D., Stryker, J., and Lambowitz, A.M. 2001. Function of the Neurospora crassa mitochondrial tyro- 


\section{Chen et al.}

syl-tRNA synthetase in RNA splicing. Role of the idiosyncratic N-terminal extension and different modes of interaction with different group I introns. J. Mol. Biol. 307: 75-92.

Myers, C.A., Wallweber, G.J., Rennard, R., Kemel, Y., Caprara, M.G., Mohr, G., and Lambowitz, A.M. 1996. A tyrosyl-tRNA synthetase suppresses structural defects in the two major helical domains of the group I intron catalytic core. J. Mol. Biol. 262: 87-104.

Myers, C.A., Kuhla, B., Cusack, S., and Lambowitz, A.M. 2002. tRNAlike recognition of group I introns by a tyrosyl-tRNA synthetase. Proc. Natl. Acad. Sci. 99: 2630-2635.

Pley, H.W., Flaherty, K.M., and McKay, D.B. 1994. Model for an RNA tertiary interaction from the structure of an intermolecular complex between a GAAA tetraloop and an RNA helix. Nature 372: $111-113$.

Shan, S., Kravchuk, A.V., Piccirilli, J.A., and Herschlag, D. 2001. Defining the catalytic metal ion interactions in the Tetrahymena ribo- zyme reaction. Biochemistry 40: 5161-5171.

Waldsich, C., Masquida, B., Westhof, E., and Schroeder, R. 2002. Monitoring intermediate folding states of the $t d$ group I intron in vivo. EMBO J. 21: 5281-5291.

Webb, A.E., Rose, M.A., Westhof, E., and Weeks, K.M. 2001. Proteindependent transition states for ribonucleoprotein assembly. J. Mol. Biol. 309: 1087-1100.

Wu, M., McDowell, J.A., and Turner, D.H. 1995. A periodic table of symmetric tandem mismatches in RNA. Biochemistry 34: 32043211.

Xia, T., McDowell, J.A., and Turner, D.H. 1997. Thermodynamics of nonsymmetric tandem mismatches adjacent to G-C base pairs in RNA. Biochemistry 36: 12486-12497.

Yaremchuk, A., Kriklivyi, I., Tukalo, M., and Cusack, S. 2002. Class I tyrosyl-tRNA synthetase has a class II mode of cognate tRNA recognition. EMBO J. 21: 3829-3840. 

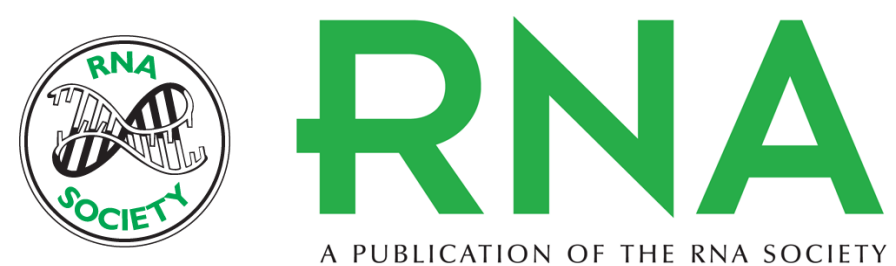

A PUBLICATION OF THE RNA SOCIETY

\section{The Neurospora crassa CYT-18 protein C-terminal RNA-binding domain helps stabilize interdomain tertiary interactions in group I introns}

XIN CHEN, GEORG MOHR and ALAN M. LAMBOWITZ

RNA 2004 10: 634-644

References This article cites 33 articles, 11 of which can be accessed free at:

http://rnajournal.cshlp.org/content/10/4/634.full.html\#ref-list-1

License

Email Alerting Receive free email alerts when new articles cite this article - sign up in the box at the

Service top right corner of the article or click here.

To subscribe to RNA go to:

http://rnajournal.cshlp.org/subscriptions 